\title{
A holistic approach to recycling of CRT glass and PCBs in Vietnam
}

\author{
Cách tiếp cận toàn diện tái chế đèn hình thủy tinh và các bo mạch in ở Việt \\ Nam
}

Policy paper

\author{
Wiesmeth, Hans ${ }^{1 *}$; Häckl, Dennis ${ }^{1}$; Do, Quang Trung ${ }^{2}$; Bui, Duy Cam ${ }^{2}$ \\ ${ }^{I}$ Faculty of Business and Economics, Chair of Economics (Allocation Theory), Technische Universität Dresden, 01062 \\ Dresden, Germany; ${ }^{2}$ Vietnam National University / Hanoi University of Science, 334 Nguyen Trai, Hanoi, Vietnam
}

\begin{abstract}
Rapidly growing quantities of e-waste (WEEE) demand the increasing attention of environmental policy all over the world. Developing countries are particularly affected by recycling and disposal activities, which are deemed harmful to health and environment. Holistic or integrated approaches to WEEE policy are required. The paper discusses first recycling technologies for glass from cathode ray tubes (CRT) and printed circuit boards (PCBs) in Vietnam. Thereafter the German approach to WEEE policy is adjusted to allow for an integrated policy. This is then adapted to allow for the recycling of used monitors and computers.
\end{abstract}

Sụ gia tăng một cách nhanh chóng số lương các chất thải tù̀ các thiết bị điện, điện tủi (WEEE) đòi hỏi sự tăng cuờng chú ý tới các chính sách môi truờng toàn cầu. Các nước đang phát triển bị tác động đặc biệt bởi các hoạt động tái chế, do nó ảnh huởng xấu tới súc khỏe và môi truờng. Các phuơng pháp tổ hợp và toàn diện đối với các chính sách quản lý chất thải điện tủi (WEEE) là đòi hỏi cấp thiết. Trong bài báo này, trước hết phân tích đánh giá các công nghệ tái chế thủy tinh đèn hình (thủy tinh CRT) và bản mach in điện tủ (PCBS) ở Việt Nam. Tiếp theo là phuong pháp tiếp cận các chính sách quản lý chất thải điện tử của Cộng hòa liên bang Đức đuợc sử dụng để điều chỉnh cho thích hợp nhà̀m đưa ra giải pháp tổ hợp có thể thích ứng cho việc tái chế màn hình Tivi và máy tính hỏng, hết hạn sử dụng và thái bỏ ở Việt Nam.

Keywords: e-waste, WEEE, CRT, PCBs, environmental policy, waste recycling, ElektroG

\section{Introduction}

The quantity of e-waste is rapidly growing - in the industrialized countries, where markets continue to be flooded with an even increasing number of electronic products, but also in the developing countries where rapid economic growth contributes toward significantly increasing quantities of e-waste entering the waste stream. This requires environmentally sound waste management taking care of the many potentially hazardous materials contained in electrical and electronic equipment. Printed circuit boards (PCBs) for example contain heavy metals such as antimony, chromium, zinc, lead, silver and copper, and cathode ray tubes (CRTs) are of special concern due to their content of lead oxide. This needs to be handled carefully in recycling processes in order to recover copper (BAN, 2007; Shinkuma and Huong, 2009).

However, e-waste recycling activities by means of simple technologies in Vietnamese villages have posed serious environmental and health hazards problems. Sediment samples show that lead levels are over two hundred times higher than normal in polluted areas. On the other hand, if such materials are properly handled, valuable resources can be recovered, thus contributing towards sustainable development and environmental improvements (Trung and Cam, 2011).

In Vietnam, e-waste is usually collected with municipal solid wastes by "waste pickers" and sold to waste recycling villages, whereby e-waste is classified and separated into three main fractions: metals, plastics and glass. The recycling activities in villages are based on simple technologies resulting in environmental pollution and health risks. In order to recover metals from e-waste the plastic is usually burned off in open places. This is happening without much awareness of health risks. The residue, for example CRT glass, is then dumped without further treatment (Trung et al., 2008). 
Thus, in order to handle the large quantities of e-waste in a safe way, effective management practices must be implemented by adopting solutions that are environmentally friendly, including recycling. As indicated above, there are several small companies and informal units in Vietnam that operate in a manner endangering human health and the environment. In those cases only the most valuable metals are recovered and the rest is discarded in an unacceptable way. The recycling processes for metals, plastics components already exist, while CRT glass recycling is quite problematic. Glass separated from e-waste (mainly from television sets or computer monitors - CRT glass) without treatment is disposed in fields, rivers and ponds (Trung et al., 2008). In addition, a great deal of the waste PCBs is illegally exported to China with only a small amount of precious metals recovered in Vietnam. Therefore, it is urgent to develop proper recycle technologies for waste CRTs and PCBs that are appropriate for Vietnam.

While first recycling technologies for CRTs and PVBs in Vietnam are available, the preconditions for implementing these technologies are still missing. According to WEEE policies in general, a holistic approach is required which suits the needs and framework conditions of Vietnam. It is the main goal of this paper to develop such a holistic approach for recycling of CRT glass and PCBs.

The following section contains a brief survey of the recycling technologies for CRT glass and PCBs developed in and for Vietnam. Thereafter the general philosophy of the EPR policy is introduced. After an investigation of the German WEEE policy, a holistic approach to WEEE policy is discussed, which is then adapted to the framework conditions in Vietnam. In particular, an integrated or holistic approach to the recycling of waste CRT glass and PCBs is developed.

\section{Technologies for recycling CRT glass and PCBs}

\subsection{Recycling of CRT glass}

In this section the possibility of recycling of CRT glass as additive material in bricks and ceramics will be briefly discussed. Moreover, a model for recycling metallic fractions in PCBs will be proposed. The technologies are suitable to be applied in small communities in Vietnam. The reader is referred to Trung and Cam (2011) for all technical details of the recycling processes.

The base of a CRT is the monitor's screen that is coated on the inside with a matrix of thousands of tiny phosphor dots. The panel glass is tinted with cobalt and nickel oxides in order to give the correct light transmission. The panel and funnel glass are coated with different kind of substances that contain heavy metals and hazardous elements. Using CRT glass in products like glass containers, tableware or glass fiber is not always feasible, because of hazardous elements such as lead, arsenic, and cadmium. In the ceramic industry the application is less restrictive and both glass from screens and cones of the monitors are potentially acceptable as secondary raw material. There- fore, CRT glass can be used (1) in brick manufacturing for saving energy; (2) in foam glass; (3) to some extent in tableware glass and (4) in glass fiber production; and (5) in ceramic bodies.

The lack of a recycling market for CRT glass in Vietnam may be due to the current legislation which imposes a restriction on the use of lead containing materials such as funnel glass in order to avoid a risk for the environment and the human health. On the other hand, the coatings adhering to CRT glass render recycling more difficult: the fluorescent powder coatings, which contain hazardous elements, are hazardous to the recycler and the environment. Moreover, organic coatings such as graphite constitute unwanted substances in the glass manufacturing industry since they interfere with the glass melting process resulting in a low quality glass product. For this reason it is very important to develop new technologies in order to claim that it is safe to use the CRT glass as secondary raw material (Andreola et al., 2007; Menad, 1999; Ching-Hwa and Chi-Shiung, 2002; Trung and Cam, 2011).

As consequence, the CRT glass to be applied as secondary raw material for the ceramic industry must be cleaned in order to eliminate the coatings. The kinescopes are reclaimed by separating the screen from the cone and successively by aspirating the harmful fluorescent powders present in the interior of the screen. Thereafter the panel and funnel glasses are washed with different chemical and water in order to remove any coating substances on the surface of the glasses. The cleaned panels can then be employed as raw material in the production of brick. The potential of using cleaned funnel glass in a base glaze formulation as substitute of "ceramic frits" in the production of X-block tiles has also been investigated (Trung and Cam, 2011).

The technical specification test for compression strength, wear abrasion resistance and water absorption demonstrated that there are no appreciable differences between the samples containing CRT glasses and regular industrial tiles. Thus, cleaned CRT glass can be used as raw material in the glaze synthesis for the ceramic industry (Trung and Cam, 2011).

\subsection{Recycling of Metallic Fractions of PCBs}

Valuable materials contained in waste PCBs should be recycled. In Vietnam a great deal of the collected PCB waste is illegally exported to China. Only metals are recovered from the small residual amount while the other parts of the PCBs are used for low-value products or incineration with hazardous effects for the environment.

However, from economic and environmental points of view, efficient and low cost processing technologies for recycling waste PCBs should be developed to reduce environmental pollution and to recover valuable materials. Pyrolysis, pyrometallurgical and biometallurgical processes, and vacuum metallurgy are common methods used in industrialized countries with high investment and operating costs. The traditional method used by the informal sector to recycle PCB waste, the hydrometallurgical method, produces a large amount of waste acid liquid 
and sludge, which is usually disposed without further treatment. Therefore, a proper technology for hydrometallurgical processes in which all chemicals and non-metal residuals are consigned to recycling is in dire need.

Trung and Cam (2011) show that copper can be recovered from waste PCBs by using various chemicals, which, in turn, can be recycled. The non-metal residual (plastic, resins, glass fibers etc.) constituting more than $70 \%$ of total weight, go to further treatment and recycling for the synthesis of thermosetting and thermoplastic resin matrix composites. As consequence, only a small fraction of residual has to be landfilled or incinerated. Nevertheless, this and related technologies have to be "standardized", refined and further developed for general applicability.

The challenge is now to "design" an environmental policy that encourages recycling of CRT glass and PCBs according to the technologies mentioned above without any risks to health and environment. Our approach will be based on the concept of a holistic policy, which emerged from the idea of "extended producer responsibility" (EPR).

The following section will first provide a brief outline of the general structure of EPR policies, in particular with respect to WEEE. Thereafter the interest will turn to the WEEE regulations in Germany. Details of the policy will be investigated and analysed with respect to their incentive structure. The philosophy of EPR - to integrate signals from along the product chain into the environmental policy - will thereby play a decisive role.

\section{The EPR approach to WEEE}

According to the guidelines of the OECD, EPR is defined as "an environmental policy approach in which a producer's responsibility for a product is extended to the postconsumer stage of a product's life cycle" (OECD, 2001; Walls, 2006). Thus, according to these guidelines, "an EPR policy is in particular characterized by the shifting of responsibility upstream toward the producer, and the provision of incentives to producers to take into account environmental considerations when designing their products" (OECD, 2001).

The critical difference of an EPR approach to other environmental policies and policy instruments is the integration of signals related to the environmental characteristics of products and production processes throughout the product chain. Thus, in most cases, this holistic approach of an EPR policy is meant to provide incentives for producers for a "design for environment" (DfE), such that, for example, their products can be easier disassembled and recycled after the product's lifetime. Nevertheless, EPR has its roots in environmental economics, and this fact is of advantage when structuring an EPR policy (Wiesmeth and Häckl, 2011).

EPR is often employed as an environmental policy in quite diverse areas. For example, EPR plays a role in car manufacturing, in waste management in general and in various areas of waste management, such as the consumption of sales packaging or WEEE, in particular. As each area has its own special conditions, the following sections will concentrate on WEEE, on extended producer responsibility regarding e-waste. The situation in Germany will be briefly investigated to explore the challenges associated with such an approach. These findings will then be related to the incentive structure, which is required for successful WEEE policies in general and for CRT glass and $\mathrm{PCB}$ recycling in Vietnam in particular.

Special attention has to be paid to the ecological effectiveness of the intended holistic approach. In principle, the regulations should provide incentives to the owners of WEEE to return the used equipment to a collection place. Then the incentives should be "handed up" to the producers to motivate them for a DfE without leaving room for leaks to semi-legal or illegal exports to developing countries.

The following case study refers to the situation in Germany with the "Act Governing the Sale, Return and Environmentally Sound Disposal of Electrical and Electronic Equipment' (ElektroG) of 2005 determining handling and treatment of WEEE. The ElektroG is the implementation of the European Directive on WEEE, enacted in 2003, into German law.

\section{Case studies}

The concrete legal framework regarding WEEE has a great influence on handling e-waste, in particular on the collection rate, on recycling processes and recycling quota. It is, first of all, remarkable to mention that from Germany (and other industrialized countries), characterized by high environmental awareness, substantial quantities of WEEE are exported to developing countries, often and sometimes incorrectly declared as reusable consumer goods. In many cases, however, these commodities turn out to be waste, even according to the lower standards of some of the importing countries. There often remain only the unsafe recycling methods of WEEE with substantial health and environmental risks - such as currently in Vietnam.

According to a study of the German Federal Environmental Agency (UBA, 2010), for example, in 2008 a quantity of approximately 50,000 $\mathrm{t}$ of monitors corresponding to two million appliances was exported. This has to be related to the $315,000 \mathrm{t}$ of new equipment of collection group 3 (IT and telecommunication equipment) that were put on the market in Germany in 2006. Additionally, according to Janz and Bilitewski (2009), 1\% of the municipal waste in Germany consists of discarded small electrical and electronic appliances, which can constitute more than $50 \%$ of the total heavy metal load in household waste with possibly severe consequences for the mechanicalbiological treatment of waste and the groundwater. One has to observe that this is happening a substantial time after the implementation of the EU Directive into German Law in 2005.

The fundamental question is, of course, why is this happening? How come rich countries with high environmental awareness and strong groups of environmentalists (for example in Germany) "export" their environmental prob- 
lems to poorer countries with the consequences mentioned above?

\subsection{An analysis of WEEE policy in Germany}

As already mentioned, the legal situation for e-waste in EU is dominated by the European Directive on WEEE, which was enacted in 2003 and which was last amended in 2008 (EU Directive, 2003). According to Article 1, its purpose is, "as a first priority, the prevention of waste electrical and electronic equipment (WEEE), and in addition, the reuse, recycling and other forms of recovery of such wastes so as to reduce the disposal of waste. It also seeks to improve the environmental performance of all operators involved in the life cycle of electrical and electronic equipment, e.g. producers, distributors and consumers and in particular those operators directly involved in the treatment of waste electrical and electronic equipment".

The relationship to EPR and, in particular, to DfE, is provided by Article 4 of the directive, which states: "Member States shall encourage the design and production of electrical and electronic equipment which take into account and facilitate dismantling and recovery, in particular the reuse and recycling of WEEE, their components and materials. In this context, Member States shall take appropriate measures so that producers do not prevent, through specific design features or manufacturing processes, WEEE from being reused, unless such specific design features or manufacturing processes present overriding advantages, for example, with regard to the protection of the environment and/or safety requirements."

In Article 7, this directive requires manufacturers and importers of electrical and electronic equipment in the member states of the EU to take back these products from the consumers for an appropriate treatment: "Member States shall ensure that producers or third parties acting on their behalf, in accordance with Community legislation, set up systems to provide for the treatment of WEEE using best available treatment, recovery and recycling techniques [...]" Provisions for financing the collection and treatment of WEEE - through the producers in the first place - and the dissemination of relevant information for the users of these equipment regarding separate collection and proper disposal conclude the directive (EUDirective, 2003, Articles 8 and 10).

The ElektroG, the implementation of the EU Directive into German law (ElektroG, 2005), contains all these regulations with further specifications and further details. Some of these specifications will now be investigated more carefully, in particular with respect to the quality and the origin of the signals and the integration of the signals into the policy.

- Product design: Article 4 of the ElektroG postulates: "Electrical and electronic equipment should, wherever possible, be designed to provide for and facilitate its disassembly, recycling and recovery, and particularly the reuse and recycling of WEEE and its components and substances [...]" The signal refers, of course, to
DfE, to the in this context important design stage for electrical and electronic equipment.

- Separate collection: According to Article 9, a separate collection of WEEE is required: "Owners of WEEE are required to place it in a collection separate from that for unsorted domestic waste." This signal addresses primarily the responsibility of the consumers and affects their transaction costs.

- Take-back system: Paragraph 8 of Article 9 demands that "producers may choose to set up and operate individual or collective take-back systems for WEEE from private households [...]" In this case, the producers are required to act, although there are some degrees of freedom not influenced by other decisions.

- Treatment: Where technically and financially feasible, a check must be made prior to treatment as to whether the waste equipment or individual components thereof can be sent for reuse (Article 11 (1)). This article refers also to the producers and leaves them again some room for making decisions, not much affected, however, by other signals or decisions.

These are some of the relevant features of the ElektroG. Obviously, the various signals refer to all stages of the product chain. If producers and consumers comply fully with these regulations, then the goals of the ElektroG could certainly be achieved. However, the "chain of incentives" provided by these articles and paragraphs has weak points, which eventually lead to the observations regarding compliance with the ElektroG.

Regarding the collection of WEEE, there is an obligation for owners of WEEE for a separate collection, which is costly, at least in terms of time needed to transport pieces of WEEE to the collection points. Without a strict enforcement, however, consumers will not necessarily comply with this regulation. The "Tragedy of the Commons" may misguide consumers to put small WEEE into the garbage collection or to "donate" other pieces of WEEE to private collectors for export. This kind of behaviour need not be in contradiction to a high environmental awareness. It results from individual rationality, which is not in line with collective rationality in this context. Moreover, commodities can be valuable enough to be reusable and reused in some developing country, but not in the country of origin. This view is supported by the required "check" prior to treatment as to whether the waste equipment can be sent for reuse (ElektroG, 2005, Article 11 (1)), leaving some room for decision-making.

In conclusion, many consumers, obliged through environmental awareness, will take WEEE to the collection points. But there still remain many opportunities to export WEEE or to discard small WEEE with the domestic garbage. Manufacturers do not have to take back and to treat WEEE, which is not returned according to these regulations. Moreover, in ambiguous cases they will decide in favour of exporting waste equipment, at least as long as this is the cheaper alternative. 
What are then the incentives of the manufacturers to implement the signals referring to product design, again without strict control from the authorities - which will not be feasible in this situation anyway? Producers will change the design, if the new design is less costly to handle then the previous one - over its lifetime including recycling. And if part of the WEEE is exported, then aggregate disassembling and recycling costs will decrease, providing even less incentive for DfE.

Thus, manufacturers are probably not very interested in collecting and treating as much WEEE as possible. They will rather try to keep their costs low by making appropriate decisions on DfE. The concept of individual producer responsibility (IPR) introduced by Rotter et al. (2009) and considered as a further development of EPR with producers bearing responsibility for their products only, could help to stimulate DfE (according to Walls, 2006, p. 31ff, for an analysis of different payment schemes in the context of IPR in the Dutch WEEE policy). However, exports of WEEE will still not be much affected by this policy change, as long as producers can enjoy lower aggregate costs for disassembling a smaller amount of WEEE. Walls (2006) also highlights in her case study on Korea (p. $35 \mathrm{ff}$ ) that changes in the product design may not only be caused by EPR regulation.

As consequence, the signals applied in the German ElektroG are not sufficiently linked together: consumers have - beyond environmental awareness - not too much interest in returning all pieces of WEEE to the official collection points, and producers seem to "profit" from a smaller quantity of WEEE to be consigned to treatment and recycling. Once again, this behaviour is induced by the "Tragedy of the Commons", and should not be fully attributed to a lack of environmental awareness. This should be taken into account when designing an incentive-compatible WEEE policy.

\subsection{An analysis of the WEEE policy in Vi- etnam}

Vietnam does not yet have specific regulations regarding e-waste. Some WEEE continues to be counted among hazardous waste in general. Generators, transporters, recyclers and disposers of hazardous waste must however register with the authorities and apply for a professional license.

Moreover, Article 67 of Law on Environment Protection (2005) requires take-back of discarded electronic and electric products and batteries. The import of waste is, in general, prohibited under environmental legislation, although certain categories of scrap materials for recovery or as secondary materials may be imported - but not ewaste.

WEEE in Vietnam is mostly discarded by selling to the collectors for dismantlement, as is the case for CRT glass and PCBs. Measures taken so far include the registration of hazardous waste generators, a licensing system for hazardous waste collection, transport and disposal and recycling activities, the development of an e-manifest system for a more effective management of hazardous waste, a frequent exchange of information among customs, environment, industry and trade authorities as well as inspection mission to ports, provinces and facilities for control of illegal import or handling of hazardous waste.

Thus, similarly to the situation with the ElektroG in Germany, the owners of WEEE constitute the first weak point. In Vietnam they are not yet sufficiently aware of the potential environmental threat associated with WEEE. As there are - at least for the time being - almost no Vietnamese producers of electronic and electrical equipment, appropriate incentives for producers refer to international companies. Therefore the question arises to what extent and under which framework conditions these global companies can be held responsible for their production activities. By competitive pressure producers will not interfere too much with import of WEEE, and as DfE cannot really be controlled and verified, producers will mainly observe the costs of their activities.

\section{An approach to an integrated WEEE policy in Germany}

In view of the above case study referring to the promotion of renewable energy sources in Germany, the following aspects should be taken into account, at least for the situation in Germany:

- If a substantial quantity of WEEE is to be recovered and consigned to recycling, then first of all the owners of WEEE should be "motivated" to return their used or end-of-life equipment to official collection points.

- There has to be a link between this motivation of the consumers and an incentive of the producers for a DfE.

Consider the following approach: owners of WEEE should be compensated with a "refund" for returning ewaste to an official collection point. Of course, the refund has to depend on the category and on some other basic characteristics of the end-of-life product. Of particular importance is the dependence of the refund on the degree of difficulty to disassemble the equipment, and perhaps on the market value of the recyclable substances.

Then there should be a "compliance scheme", similar to the compliance schemes for packaging waste in Germany, which producers have to join and which takes back WEEE and consigns it to treatment and recycling (Walls, 2006, p. 35ff, for the WEEE policy in Korea). This compliance scheme receives fees from the manufacturers, which depend also on the characteristics of the products mentioned above. Moreover, this scheme is in charge of issuing the refunds to the consumers.

The consequence of this approach is a sequence of signals from the product chain, which are linked together: the consumers have an incentive to return WEEE to official collection points and "leakage" to export markets will be reduced. Then, as the refunds depend on certain characteristics of the WEEE, fees to be paid to the compliance scheme and possibly the prices of the new products will 
depend on these characteristics as well. Therefore, if a DfE reduces life-time costs, producers have an incentive to change the design of their products.

Thus, there is a closed link of signals from product design to take back and recycling, which even helps to reduce illegal exports of WEEE. In addition to that this approach opens, in the sense of PFI, investment opportunities for recycling companies and companies to operate the compliance scheme.

As mentioned above, the concrete values for the refunds and the fees remain a critical issue. Thus, it may well happen that the fees to be paid by the producers to the compliance scheme are too small to have any effect on DfE. Or, alternatively, the refunds to the owners of WEEE may be too low and private collectors may offer higher prices for WEEE to be exported as reusable equipment. Similarly, refunds and fees can be too high resulting in "imports" of WEEE and so on. Therefore, it remains the duty of the authorities to monitor the detailed development of the WEEE policy and of related activities. Furthermore, policymakers have to be aware of other factors influencing companies' design decisions, such as consumer preferences or resource prices, when setting up the fee-refund system.

\section{Policy for CRT Glass and PCB Re- cycling in Vietnam}

Regarding CRT glass it should be observed that the quantity of monitors with CRT glass will decrease due to the new flat screens which have more and more replaced the cathode ray tubes in the last years. Nevertheless there still is a large quantity of "old" monitors which will likely end up in countries such as Vietnam. And, not to forget, the "new" flat screens may pose new challenges for the environment. Therefore, the following recommendations will focus on a policy for used TV sets and used Personal Computers (PCs) in general, although the in Vietnam currently available recycling technologies refer to those introduced earlier.

Vietnam could proceed as follows regarding a first approach towards a holistic policy for old PCs in general, and CRT glass and PCBs in particular:

\section{Handling of waste electronic equipment:}

- Owners of old PCs should be motivated to return their waste equipment to an official collection point; more precisely: anyone delivering waste electronic equipment (PCs and monitors) to a collection point should get a monetary compensation, which could depend on the size of a returned monitor.

- Official collection points should be established throughout the major cities in the vicinity of households, administrative units and business districts.

- Public authorities should be in charge to transfer the waste electronic equipment to licensed recycling companies, operating according to environmentally safe standards with the technologies for CRT glass and PCB recycling.

\section{Financing these operations:}

- At least part of the financing of these operations could come from selling the recycled CRT glass to the brick and ceramics industry and from proceeds from the recovery of precious metals from the PCBs. For this, however, the public authorities have to grant permission to markets for these secondary raw materials.

- An additional part of the revenue required for financing this recycling scheme could come from the (international) producers of this equipment: preferably, the manufacturers of the equipment exported to Vietnam could be asked to support these recycling schemes in the context of their sustainability strategy; alternatively an import tax could be imposed on this electronic equipment, depending on environmentally relevant characteristics.

\section{Raising environmental awareness in general:}

- Environmental awareness with respect to WEEE should be raised; appropriate measures point to educational activities and information at the "point-of-sale" of electrical and electronic equipment.

The incentives associated with this policy are as follows: first of all, owners of waste electronic equipment have an incentive to return this equipment. The recycling companies ideally organized as private companies with public supervision also have an incentive to recycle old PCs and monitors and to sell the secondary materials. Moreover, the producers of electronic equipment receive signals for DfE, for a design for environment, if the their financial contribution to the recycling schemes in Vietnam or the import tax depends not only on the quantity of commodities exported to Vietnam, but also on environmentally relevant characteristics of these products.

Therefore, this policy is "integrated" or "holistic" in the sense that it covers the whole product chain - at least to an extent which is feasible for Vietnam, and in the sense that the signals from the various parts of the product chain are linked: the monetary compensations for returning waste equipment, the financial situation of the recycling companies, the revenue from the secondary recycling markets, the import taxes or the contributions of the international producers to the recycling schemes are closely related and affect each other. Of course, the "art of WEEE policy making" consists also in finding the "right" values for the various monetary signals.

Taking these issues into account should help to establish an appropriate WEEE policy which will help to setup a truly holistic WEEE policy in near future.

\section{Final remarks}

The above considerations demonstrated that the difficulties with EPR policies in general and with WEEE policies 
in particular are hidden in the interaction with the economic agents, with the consumers, the producers, and in some cases with the recyclers. Policies provide certain incentives to the economic agents and thus influence their behaviour - sometimes in an unintended way.

As consequence, in order to arrive at a feasible and ecologically effective policy for recycling of CRT glass and PCBs in Vietnam, one has to take into account the behaviour of consumers and producers, in particular with regard to their interaction with the policies and instruments used to reach the desired goals. However, information deficits due to external effects create some difficulties associated with the implementation of these policies and require a

[1] Andreola, F., Barbieri, L., Corradi, A., Lancellotti, I. 2007. CRT Glass State of the Art - A Case Study: Recycling in Ceramic Glazes. Journal of the European Ceramic Society 27:1623-1629

[2] BAN 2007. Basel Action Network. Silicon Valley Toxics Coalition. Exporting Harm: The High-Tech Trashing of Asia. http://www.ban.org/e-waste/ technotrashfinalcomp.pdf (retrieved October 2007)

[3] Ching-Hwa, L., Chi-Shiung, H. 2002. Recycling of Scrap Cathode Ray Tubes. Environ. Sci. Technol. 36:69-75

[4] EEG 2009. Renewable Energy Sources Act, Germany.http://www.bmu.de/english/renewable_energy/do wnloads/doc/20026.php (retrieved May 2011)

[5] ElektroG 2005. Act Governing the Sale, Return and Environmentally Sound Disposal of Electrical and electronic Equipment (Electrical and Electronic Equipment Act). Fed Law Gazette 2005:762-774. http://www.bmu.de/files/pdfs/allgemein/application/ pdf/elektrog_uk.pdf (retrieved May 2011)

[6] EU Directive 2003. Directive of the European Parliament and of the Council on WEEE. http://eurlex.europa.eu/LexUriServ/LexUriServ.do?uri=OJ:L: 2003:037:0024:0038:EN: PDF (retrieved May 2011)

[7] Janz, A., Bilitewski, B. 2009. WEEE in and outside Europe - hazards, challenges and limits. In: Lechner, P. (Ed.), Prosperity Waste and Waste Resources. Proceedings of the $3^{\text {rd }}$ BOKU Waste Conference, BOKU-University of Natural Resources and Applied Life Sciences, Vienna, 113-122

[8] Menad, N. 1999. Cathode Ray Tube Recycling. Resources, Conservation and Recycling 26:143-154

[9] OECD 2001. Extended producer responsibility: a guidance manual for governments. OECD, Paris. http://www.oecd.org/LongAbstract/0,3425,en_2649_ 34395_2405199_1_1_1_1,00.html (May 2011) continuous monitoring. In the case considered here this refers mainly to the price signals used in the policy.

\section{Acknowledgement}

This paper results from presentations and discussions in the Workshop "Avoidance of E-Waste as an Important Issue for Waste Management" at Hanoi University of Science in December 2011, funded by DAAD and Hanoi University of Science.

\section{Literature}

[10] Rotter, V., Schill, W., Chancerel, P. 2009. Implementing individual producer responsibility (IPR) under the European WEEE directive - experiences in Germany. In: 2009 IEEE International Symposium on Sustainable Systems and Technology. ISSST, Tempe, AZ, USA, May 18-20, 1-6

[11] Shinkuma, T., Huong N. 2009. The Flow of E-waste Material in the Asian Region and a Reconsideration of International Trade Policies on E-waste, Environmental Impact Assessment Review 29:25-31

[12] Trung, D. et al., 2008. Building up the solution for ewaste management and reuse in Vietnam in the period from 2006 to 2010, Final report (Vietnamese), MONRE project code QMT 06.01

[13] Trung, D., Cam, B. 2011. Feasibility of Research of E-Waste Recycling Processes in Vietnam: An Investigation with CRT Glass and PCBs at the Small Communities, Discussion Paper, Hanoi University of Science

[14] UBA 2010. Export of WEEE, German Federal Environmental Agency, Press release No. 12/2010. http://www.umweltbundesamt.de/uba-info-pressee/e-pinfo10.htm (retrieved May 2011)

[15] Walls, M. 2006. Extended producer responsibility and product design: economic theory and selected case studies. Discussion Paper, Resources for the Future, Washington DC. http://www.rff.org/ documents/rff-dp-06-08-rev.pdf (retrieved May 2011)

[16] Wiesmeth, H., Häckl, D. 2011. How to successfully implement extended producer responsibility: considerations from an economic point of view. Waste Management \& Research, 29(9):891-901

[17] Yoshida, F., Yoshida, H. 2010: Japan, the European Union, and waste electronic and electrical equipment recycling: key lessons learned. In: Environmental Engineering Science 27(1):21-28 